\title{
A POLÍTICA CULTURAL COMO VIA DE LEGITIMAÇÃo DE UM PROJETO POLÍTICO: o Teatro de Cultura Popular (TCP) e os governos de Miguel Arraes (1960-1964)
}

\author{
Luiz Felipe Batista Genú* \\ Camila Maria de Araújo Melo**
}

RESUMO: A investigação apresentada nesse artigo tem como propósito analisar de que formas o teatro pode ser utilizado como uma via de construção de legitimidade para um projeto político. Para tanto, seguiremos parte da trajetória do Teatro de Cultura Popular (TCP), grupo fundado na década de 1960, como parte da política cultural posta em prática pela Prefeitura Municipal do Recife durante a gestão de Miguel Arraes (1960-1962), por meio do Movimento de Cultura Popular (MCP) do Recife. Consideramos que devido ao seu aspecto intrinsecamente político, por tratar-se de um tipo de assembléia, a arte teatral despontou como um dos projetos principais dentro da política cultural das esquerdas políticas em Pernambuco na década de 1960.

PALAVRAS-CHAVE: Teatro de Cultura Popular; Política cultural; Cultura popular; Legitimação.

\section{Cultural politics as a way of legitimizing a political project: the Theater of Popular Culture (TCP) and the governments of Miguel Arraes (1960-1964)}

ABSTRACT: The research presented in this article aims to analyze in what ways theater can be used as a way of building legitimacy for a political project. Therefore, we will follow part of the path of the Teatro de Cultura Popular (TCP), a group founded in the 1960s, as part of the cultural policy implemented by the Mayor's Office of Recife during Miguel Arraes' administration (1960-1962), through the Movimento de Cultura Popular (MCP). For having an intrinsically political aspect, since it is a type of assembly, we consider that theatrical art has emerged as one of the main projects within the cultural policy of the political left in Pernambuco in the 1960s.

KEYWORDS: Teatro de Cultura Popular; Cultural policy; Popular culture; Legitimation.

\section{La política cultural como vía de legitimación de un proyecto político: el Teatro de Cultura Popular (TCP) y los gobiernos de Miguel Arraes (1960-1964)}

RESUMEN: La investigación presentada en ese artículo tiene el propósito de analizar de qué formas el teatro puede ser utilizado como una vía de construcción de legitimidad para un proyecto político. Para ello, seguiremos parte de la trayectoria del Teatro de Cultura Popular (TCP), grupo fundado en la década de 1960, como parte de la política cultural puesta en práctica por el Ayuntamiento de Recife a lo largo de la gestión de Miguel Arraes (1960 - 1962) a través del Movimento de Cultura Popular (MCP) de Recife. Consideramos que, debido a su aspecto intrínsecamente político, por tratarse de un tipo de asamblea, el arte teatral surgió como uno de los proyectos principales dentro de la política cultural de las izquierdas políticas en Pernambuco en la década de 1960.

PALABRAS CLAVE: Teatro de Cultura Popular; Política cultural; Cultural popular; Legitimación.

\footnotetext{
*Mestre em História pelo Programa de Pós-Graduação em História da Universidade Federal de Pernambuco. Atualmente é professor da educação básica da rede particular de ensino do Recife. Contato: Rua Professor Bandeira, 610, Recife, Pernambuco, Brasil. E-mail: felipegenu@ hotmail.com. ORCID: https://orcid.org/00000001-7939-672X.

**Mestra em História pelo Programa de Pós-Graduação em História da Universidade Federal de Pernambuco. Atualmente, é professora da rede particular de ensino do Recife. Contato: Rua Professor Bandeira, 610, Recife, Pernambuco, Brasil. E-mail: camilama_melo@ @otmail.com. ORCID: https://orcid.org/0000-0003-1882-705X.
} 


\section{Introdução}

Recife, 21 de setembro de 1964. Rua Visconde de Suassuna, bairro de Santo Amaro. O jovem Carlos chegou ao prédio onde desde 1943 funcionava o quartel da $2^{\text {a }}$ Companhia de Guardas do Exército. Engenheiro agrônomo e ator, Carlos vinha atender à intimação que recebera convocando-o para que prestasse esclarecimentos sobre suas atividades anteriores e posteriores ao golpe civil-militar de 1964. Segundo consta no "Termo de perguntas ao indiciado", o foco do depoimento recaiu sobre suas ligações com "elementos comunistas" e suas atividades de locutor da Rádio Universitária do Recife ${ }^{1}$.

É pouco provável que a proximidade espacial entre o edifício no qual residia com a esposa, na Avenida Conde da Boa Vista ${ }^{2}$, e o quartel tenha tornado o percurso mais fácil. Afinal, desde o início dos expurgos conduzidos por oficias das forças armadas, Carlos vira pessoas próximas a si serem denunciadas, presas e obrigadas a responder a um Inquérito Policial Militar (IPM). Alguns optaram pela fuga e pela vida clandestina como maneira de evitar as prisões, caso do seu amigo - e diretor do Teatro de Cultura Popular do Recife (TCP) - Luiz Mendonça. Outros haviam conseguido evitar a condenação a uma pena de reclusão, mas marcados pelo epíteto de "subversivo" ou "comunista" sofreram processos administrativos e perderam seus empregos, como o também ator - e membro do TCP - Joacir Castro.

Após identificar-se, Carlos foi conduzido a uma sala com poltronas de madeira, onde foi informado que deveria permanecer até ser chamado pelo oficial que conduzia as investigações em Pernambuco ${ }^{3}$. Segundo recordou décadas depois, não se tratava de uma cela convencional, com grades e pouca iluminação, mas o jovem ator foi obrigado a permanecer ali até ser ouvido pelo interrogador. Qualquer tipo de comunicação com o exterior estava proibida. Ser paciente era o que lhe restava. À medida que o tempo passava, eram-lhe servidas as refeições naquela sala com poltronas de madeira. Almoço, jantar, café da manhã, almoço, jantar e entre elas havia o tempo para imaginar como seria o interrogatório. Que tipo de perguntas seriam feitas? Ou, talvez mais importante, do que era acusado?

Apenas na madrugada do segundo dia Carlos foi ouvido. Conduzido à sala de depoimentos, foi apresentado ao Tenente-coronel Hélio Ibiapina, responsável por conduzir os Inquéritos Policiais Militares (IPMs) em Pernambuco, e ao Capitão Noaldo Alves Silva, que serviria como escrivão. O Ten.-cel. Ibiapina iniciou o interrogatório com perguntas gerais: nome, filiação, endereço e profissão. Em seguida, Carlos foi questionado se possuía inimigos, ao que respondeu: não. Terminada a rodada de perguntas iniciais, Ibiapina parece tentar traçar 
um perfil político de Carlos, indagando o que ele achava dos "extremismos", particularmente o nazismo, o fascismo e o marxismo. Carlos respondeu de maneira breve ao Ten.-cel., afirmando abominar todo tipo de extremismo devido à sua formação cristã. $\mathrm{O}$ interrogador insiste no direcionamento das questões, perguntando se Carlos seria capaz de defender os regimes políticos e econômicos em vigor nos países da "Cortina de Ferro" e se era um admirador de Fidel Castro. Novamente, o depoente procura se distanciar do espectro político da esquerda, asseverando que não defenderia os países de regime socialista e que não era admirador do líder cubano.

A referência a Cuba criou a oportunidade perfeita para Carlos fortalecer sua defesa. Segundo transcreveu o capitão Noaldo Silva, após negar qualquer admiração por Fidel Castro, o ator afirmou que:

[...] quando trabalhava no Teatro Popular do Nordeste, participou de luta aberta contra o partidarismo vermelho que havia no Recife à época do Teatro de Cultura Popular, quando levavam a peça "Julgamento em Novo Sol". No referido Teatro Popular do Nordeste, o depoente representou a peça "A bomba da Paz", que era um libelo contra o comunismo e a cubanização.

A construção narrativa realizada por Carlos a partir de suas memórias da temporada teatral de 1962 - quando os referidos espetáculos estiveram em cartaz no Recife - lhe permitiu criar um refúgio das tentativas do Ten.-cel. Ibiapina de situá-lo à esquerda do espectro político, já que o depoente se colocou como contrário ao que chamou de "partidarismo vermelho" numa alusão ao comunismo/socialismo. O que não impediu que o interrogador insistisse, testando a solidez do álibi do jovem ator, principalmente devido às atividades de locutor da Rádio Universitária desempenhadas por Carlos enquanto estudante da Universidade Federal Rural de Pernambuco.

A grande questão para o interrogador passou a ser como seria possível alguém que se intitulara um adversário do "partidarismo vermelho" ter narrado programas de rádio que, segundo as denúncias, "insuflavam a luta de classes"? Habilmente, Carlos justifica sua participação nos referidos programas como limitada à narração da pauta que era determinada pelos produtores do programa. Tratava-se de programas educativos redigidos por pessoas pertencentes à Universidade Federal de Pernambuco e ao Movimento de Cultura Popular do Recife (MCP)

Ao fim, numa última tentativa de encurralar o depoente, Ibiapina pergunta que fatos ou provas ele poderia apresentar de sua inocência. Novamente, Carlos se refere as suas lutas contra o movimento subversivo por meio do teatro como um dos principais atestados de sua 
inocência. Após conferir e assinar o "Termo de perguntas ao indiciado", Carlos pôde retornar para sua esposa, grávida de oito meses.

O episódio narrado anteriormente é significativo sob vários aspectos. Em um primeiro plano, nos permite acompanhar parte dos desdobramentos advindos do golpe civil-militar de 1964 para o cidadão brasileiro: intimações para prestar esclarecimentos sobre acusações baseadas em denúncias que muitas vezes eram desconhecidas do acusado ${ }^{4}$. Permite-nos imaginar o medo de não saber o próprio destino após adentrar uma instituição militar na condição de "depoente", bem como a necessidade de estar atento às armadilhas que surgiam durante os interrogatórios, empregando táticas que ajudassem a escapar do interrogador ${ }^{5}$.

Em segundo plano, o trecho do depoimento que aparece transcrito de maneira direta destaca a importância do caráter político da arte teatral. Caráter político que, como demonstrou Denis Guénoun, não reside apenas naquilo que é mostrado no palco, mas, antes de tudo, em seu cunho de reunião pública, necessária para que essa arte possa ser realizada de maneira plena ${ }^{6}$. Afinal, o teatro não é apenas uma forma de literatura recheada de didascálias: ele é o espetáculo encenado para uma plateia ${ }^{7}$.

É exatamente a característica de assembléia aberta a todo e qualquer cidadão disposto a se deslocar até o local da encenação que fortalece o argumento de defesa utilizado por Carlos: qualquer esforço mínimo de investigação empreendido pelo Exército comprovaria que ele de fato desempenhara dois papeis na peça $A$ Bomba da Paz. ${ }^{8}$ Observaria ainda que a referida peça tecia críticas à maneira como alguns grupos, tanto da direita quanto da esquerda política da década de 1960, procuravam impor e legitimar suas visões e projetos de sociedade - inclusive havia personagens que caricaturavam líderes comunistas famosos, como Fidel Castro e Luís Carlos Prestes.

Sub-repticiamente, é possível perceber no depoimento que o processo de legitimação política em Pernambuco não deixou de envolver o campo teatral, afinal há ainda um grupo de teatro que aparece na fala de Carlos como parte do que denomina "partidarismo vermelho": o Teatro de Cultura Popular (TCP). É sobre o TCP e seu papel na legitimação do projeto político desenvolvido em Pernambuco durante os governos de Miguel Arraes na década de 1960 - como prefeito do Recife e, a partir de 1963, governador de Pernambuco - que ajustaremos nosso escopo. 


\section{Uma nova política cultural entra em cena}

Cinco anos antes do episódio narrado anteriormente, em 15 de dezembro de 1959, tomou posse na Câmara de Vereadores do Recife o prefeito eleito, Miguel Arraes. Os jornais da época destacaram que aquela era a segunda solenidade de posse de um prefeito eleito desde o restabelecimento da autonomia política do Recife. A anterior havia sido a posse de Pelópidas da Silveira, em $1955^{9}$.

O discurso de Miguel Arraes durou pouco mais de 15 minutos e versou sobre os desafios que figuravam no horizonte da gestão municipal, considerando as grandes necessidades da cidade e de seus habitantes e o curto orçamento de que dispunha. Não obstante, externou sua felicidade por ocupar o cargo e a alegria que sentia em poder viabilizar projetos "em favor do povo". Destacou a importância da união entre o executivo e o legislativo municipal e a busca por verbas junto ao governo federal. $\mathrm{O}$ otimismo de parte da população do Recife em relação ao novo prefeito foi demonstrado nas comemorações que tomaram as ruas do centro da cidade naquela noite. Jornais do período registraram que parecia um carnaval, já que houve desfiles de blocos, clubes, maracatus, escolas de samba e caboclinhos ${ }^{10}$.

A eleição de Miguel Arraes para a prefeitura foi a terceira vitória eleitoral seguida segunda no âmbito municipal - da Frente do Recife, que consistiu em uma sequência de acordos de coalizão política firmados entre partidos em Pernambuco a cada um dos pleitos eleitorais disputados entre 1955 e $1963^{11}$. Importante destacar que a hegemonia da articulação política nessa coligação era de partidos de esquerda - notadamente do Partido Socialista Brasileiro (PSB) e o Partido Comunista Brasileiro (PCB). Este último, mesmo sem registro eleitoral, mantinha-se organizado e atuante politicamente ${ }^{12}$.

Uma vez empossado, Miguel Arraes deu continuidade e intensificou o projeto de melhorias da cidade do Recife, iniciado pelo seu antecessor no cargo, Pelópidas da Silveira que também fora eleito com o apoio da Frente do Recife. O primeiro passo foi estabelecer quais as áreas prioritárias a serem cuidadas, como os sistemas de abastecimento de água e de distribuição de energia elétrica, a ampliação da rede de esgotos e a insuficiência de moradias para a população mais pobre ${ }^{13}$. A definição das áreas prioritárias foi baseada em levantamentos feitos por assessores técnicos da prefeitura e nas reivindicações entregues por representantes da população em audiências públicas realizadas no Teatro de Santa Isabel ${ }^{14}$. 
Percebe-se que as forças progressistas e de esquerda que apoiavam a administração municipal de Miguel Arraes iam aos poucos inserindo mudanças na forma como era gerida a "coisa pública" em Pernambuco. Tendência que continuou quando Arraes foi eleito governador do estado, cargo que ocupou a partir de janeiro de 1963. A forma como conduziu as disputas entre os sindicatos de trabalhadores rurais, os senhores de engenho e os usineiros com base na negociação entre as partes e dentro da legalidade - é outro exemplo das modificações ocorridas ${ }^{15}$.

No entanto, não se deve pensar que essas mudanças aconteceram de forma fácil ou tranquila. As forças políticas representadas por Miguel Arraes enfrentaram forte oposição de setores sociais considerados na época como conservadores, agrupados, sobretudo, nas fileiras da União Democrática Nacional (UDN). A resistência que aquele projeto político enfrentava se devia, ao menos em parte, às reformas sociais que tentava implantar e à participação de socialistas e comunistas.

A aliança entre setores progressistas da sociedade pernambucana com grupos de esquerda pertencentes ao PCB e ao PSB foi bastante explorada pelos opositores de Miguel Arraes, devido à concepção - culturalmente hegemônica na época - de que socialistas e comunistas eram sinônimo de subversão dos valores políticos e religiosos nacionais ${ }^{16}$. Logo, devemos considerar a existência de um "sistema central de práticas, significados e valores" 17 que, como afirma Raymond Williams, são "capazes de constituir um sentido de realidade para a maioria das pessoas"18, no qual a presença de comunistas e socialistas como atores no cenário político era entendida como algo que punha em risco a legalidade constitucional ${ }^{19}$.

Com frequência, publicações veiculadas pela imprensa conferiam a Miguel Arraes a alcunha de líder comunista, prestes a iniciar um processo irreversível de "cubanização" do Brasil a partir do Nordeste ${ }^{20}$. Podemos verificar esse tipo de abordagem em matéria da revista O Cruzeiro, publicada em julho de 1962 - momento em que o prefeito do Recife aparecia como forte pré-candidato da Frente do Recife para as eleições majoritárias no Estado, em outubro próximo.

Assinada pelo jornalista Glauco Carneiro, a matéria é aberta por uma foto de página inteira na qual Miguel Arraes aparece sério, de perfil. Na parte superior esquerda foi escrito "Nordeste, SINAL VERMELHO" e na página ao lado, em letras capitais, aparece o título da matéria: "Pernambuco, DEMOCRACIA EM PÂNICO"21. Já no parágrafo introdutório, o jornalista vaticina: “[..] A 7 de outubro, o PC, provavelmente, encerrará a luta de 40 anos contra a democracia: Miguel Arrais [sic] deverá se tornar governador do Estado, passando aos 
vermelhos o controle do bastião mais importante da defesa do Atlântico Sul e cubanizando o Nordeste" 22 . Detalhe: na época, O Cruzeiro era a revista de maior circulação no Brasil ${ }^{23}$.

Um leitor que se deparasse com a publicação referida e desconhecesse o que acontecia em Pernambuco no período estaria bastante inclinado a acreditar na suposta conspiração comunista liderada por Miguel Arraes. Principalmente considerando que matérias semelhantes circularam em outros veículos da imprensa, especialmente no período eleitoral, como nos periódicos Diário de Pernambuco e Jornal do Commércio. Também os partidários do adversário de Miguel Arraes no pleito de 1962, João Cleofas, reforçaram a ligação entre o candidato da Frente do Recife e a imagem de autoritarismo e violência dos regimes socialistas europeus, como evidencia o episódio em que dois painéis representando o muro de Berlim foram erguidos no centro do Recife poucos dias antes das eleições. Acima da imagem do muro uma mensagem conclamava os transeuntes a imaginarem como seria se ali fosse erguido um muro similar ao da capital alemã ${ }^{24}$.

Apesar das sucessivas vitórias eleitorais em 1959 e 1962, é possível que o grupo reunido em torno de Miguel Arraes tenha percebido que era preciso não apenas pôr em prática medidas que respondessem aos desafios sociais daquele presente, mas também criar uma política cultural que legitimasse seu projeto político e social. Esse processo de legitimação precisaria oferecer um contraponto à imagem de representante da subversão disseminada por publicações semelhantes às comentadas acima.

Essa política cultural seria responsável por desenvolver os meios para operar uma profunda mudança nos sistemas de percepção e avaliação da realidade dos indivíduos - aquilo que Pierre Bourdieu chamou de habitus ${ }^{25}$. Disseminar novos signos, em consonância com o seu projeto político e social, para fortalecer sua posição no campo das relações de poder simbólico do período ${ }^{26}$. Mas, se o que era preciso fazer estava claro, faltava definir a maneira fazê-lo.

\section{O Movimento de Cultura Popular (MCP): uma nova política cultural para o Recife}

Norberto Bobbio define a política cultural como uma "planificação da cultura por parte dos políticos" visando ganhos no campo do poder $^{27}$. Já Philippe Urfalino chama a atenção para o fato de que as políticas públicas da cultura - ou seja, quando há a intervenção estatal no referido campo - são apenas um dos aspectos das políticas culturais ${ }^{28}$. Isso porque antes da formalização das estruturas administrativas, da contratação de pessoal e da definição 
de propostas norteadoras, a concepção (ou concepções) de cultura que orientará a efetivação da política cultural em uma política pública surge nas relações travadas entre os membros do campo cultural e destes com os representantes do Estado ${ }^{29}$. Embora um pouco distintas, ambas as definições remetem à aproximação entre o campo cultural e o político que tende a ocorrer em um determinado arranjo social, a partir da existência de pré-disposições dos membros desses campos baseadas nos possíveis ganhos - políticos ou culturais.

No tocante à política cultural do Recife, com a eleição de Miguel Arraes para prefeitura entra em cena um grupo de intelectuais e artistas, atraídos pelas mudanças sinalizadas na nova administração municipal em relação à gestão do campo cultural local. $\mathrm{O}$ primeiro passo da aliança foi a formação de uma entidade civil chamada Movimento de Cultura Popular (MCP). Seu objetivo era trabalhar em convênio com a Prefeitura do Recife no desenvolvimento e aplicação de uma nova política cultural que combinava educação formal, atividades artísticas e lazer.

Abelardo da Hora, Ariano Suassuna, Germano Coelho, Norma Coelho, Anita Paes Barreto, Hermilo Borba Filho e Paulo Freire eram alguns dos envolvidos na criação do movimento ${ }^{30}$. Tendo em vista a variedade de ações e áreas para intervir, o MCP foi dotado de uma estrutura complexa, composta por diferentes departamentos e conselhos administrativos subordinados à uma direção ${ }^{31}$. A divisão de teatro do $\mathrm{MCP}$, por exemplo, era um dos departamentos que integravam o Departamento de Formação da Cultura (DFC) - que possuía outras nove divisões ${ }^{32}$.

Entre os projetos encabeçados pela Divisão de Teatro do MCP a formação de um grupo de teatro próprio figurou entre os principais objetivos da política cultural posta em prática pelo movimento, juntamente com a criação de novos espaços para encenações teatrais na cidade. A partir de agosto de 1961, sob o nome provisório de Teatro Experimental de Cultura (TEC), teve início a trajetória do grupo que já no ano seguinte recebeu sua denominação definitiva: Teatro de Cultura Popular (TCP). Rapidamente, o teatro assumiu o protagonismo da crítica social e da defesa de novos valores feita pelo MCP.

\section{O Teatro de Cultura Popular (TCP) e a (re)significação de uma realidade}

Principal projeto da Divisão de Teatro do MCP, a direção do Teatro de Cultura Popular em seus primeiros momentos - quando ainda era chamado de Teatro Experimental de Cultura (TEC) - ficou a cargo do responsável por aquela divisão, o encenador e ator, Luiz 
Mendonça. Foi sob a tutela de Mendonça que o grupo começou a pensar o seu projeto teatral após os desligamentos de Hermilo Borba Filho e Ariano Suassuna do MCP. Segundo recordou a atriz Ilva Niño: a intenção era trabalhar com peças teatrais que, sob a ótica do grupo, abordavam a realidade brasileira de então ${ }^{33}$, para, a partir de sua encenação fazer reivindicações, complementou Moema Cavalcanti, também membro do $\mathrm{TCP}^{34}$.

Embora houvesse muita disposição entre os jovens que integravam o TCP, faltava-lhes experiência para desenvolver aquele projeto teatral ${ }^{35}$. Nesse aspecto, foi fundamental a vinda do Teatro de Arena de São Paulo, - grupo já familiarizado com a encenação de espetáculos que abordavam temas políticos e sociais -, ao Recife em outubro de 1961, sob o patrocínio da Prefeitura e do MCP. Primeiro por oportunizar a troca de experiências entre os grupos ${ }^{36}$, e em segundo lugar, porque dois integrantes do Arena foram convidados à voltar ao Recife para trabalharem no TCP no início de 1962: o ator Nelson Xavier e a figurinista Ded Bourbonnais.

Em entrevista ao Diário de Pernambuco, em 13 de fevereiro de 1962, Nelson Xavier afirmou que, enquanto membro do TCP, queria trabalhar em cooperação com escritores, dramaturgos e atores locais no desenvolvimento de pesquisas que permitissem criar uma nova dramaturgia, "que reflita a realidade nordestina" ${ }^{37}$. A presença de Nelson Xavier acabou por potencializar a perspectiva inicial presente entre os membros do TCP no sentido de direcionar seus trabalhos para a criação de uma estética identificada com um teatro didático, que motivasse o debate político.

Essa postura artística inseriu o TCP no universo de grupos de artistas e intelectuais representantes das classes médias urbanas no Brasil dos anos 1960 que, ao questionarem o processo de modernização capitalista excludente pelo qual o país vinha passando, se propuseram a buscar alternativas de desenvolvimento social - caso do já citado Teatro de Arena e dos Centros Populares de Cultura (CPCs) da União Nacional dos Estudantes (UNE). Esses intelectuais e artistas, que em sua maioria tinham ligações com as forças políticas de esquerda, acreditavam que estava em curso uma revolução social na qual não podiam deixar de se engajar ${ }^{38}$.

A busca por um modelo alternativo de sociedade, para esses grupos, passava pela construção de um "homem novo", capaz de agir em prol da transformação da sociedade brasileira. O modelo para esse "homem novo", segundo Marcelo Ridenti, foi encontrado no passado, numa idealização feita por intelectuais e artistas sobre as populações das áreas rurais que, por viverem longe das cidades, eram vistas como portadoras de tradições e valores característicos do povo brasileiro $^{39}$. Ridenti é enfático ao afirmar que esses grupos de 
intelectuais e artistas urbanos "identificavam-se com os deserdados da terra, ainda no campo ou migrantes nas cidades, como principal personificação do caráter do povo brasileiro, a quem seria preciso ensinar a lutar politicamente" ${ }^{\natural 0}$.

Dessa maneira, podemos entender que ao tomarem o nome de Teatro de Cultura Popular a intenção do grupo teatral mcpista não era a de apenas criar um projeto cênico pautado nas expressões culturais entendidas como "originárias do povo" - como o cavalo marinho ou o reisado - muito menos colocar representantes desse povo - ou seja, de grupos economicamente menos favorecidos - para atuar em espetáculos escritos pelos intelectuais do movimento, embora pessoas de qualquer grupo social pudessem participar do TCP. A concepção de cultura popular do TCP, assim como para o MCP, era a de uma cultura que "se fazia pelo povo" ${ }^{41}$. Como coloca Sebastião Uchoa Leite, o conceito de cultura popular passa a designar, no período em tela, a instrumentalização das expressões artísticas e culturais para fins educacionais, no sentido de despertar uma consciência social e política nos grupos economicamente desfavorecidos definidos genericamente como "povo"42.

Logo, se o objetivo era educar a consciência social e política do povo nada mais apropriado do que empregar o teatro nesse intuito, afinal, como nos referimos anteriormente, o teatro é, em seu cerne, um tipo de assembléia. Analisando a breve carreira do Teatro de Cultura Popular (1961 - 1964), identificamos três formas de ação que contribuíram para legitimar a administração de Miguel Arraes: a escolha da temática dos espetáculos, os programas distribuídos à plateia e a criação de autos de conscientização e esquetes teatrais.

\section{a) A temática das peças}

Nesta sessão, nos centraremos nos dois principais espetáculos do Teatro de Cultura Popular: Julgamento em Novo Sol e A Incelença. Os temas das peças montadas pelo Teatro de Cultura Popular, em sua maioria, giraram em torno do cotidiano dos trabalhadores rurais e dos desafios que estes enfrentavam. Caso de Julgamento em Novo Sol, adaptada do original Mutirão em Novo Sol, escrito por Nelson Xavier e alguns colegas do Teatro de Arena de São Paulo $^{43}$. Baseada em um caso de disputa de terras entre agricultores e latifundiários do interior do estado de São Paulo ${ }^{44}$ essa peça permitiu ao TCP abordar as relações trabalhistas entre o latifundiário e os trabalhadores da fazenda, também conhecidos por colonos. A ação da peça, como o título adaptado revela, se passa durante o julgamento do líder camponês que tentava impedir o despejo das famílias de agricultores que viviam nas terras do coronel Porfírio ${ }^{45}$. 
À medida que os personagens são convocados para depor, a ação que se passa no tribunal é entrecortada pelas encenações das situações descritas nos depoimentos pelas testemunhas. Os episódios retratados na peça - um total de treze momentos retrospectivos ${ }^{46}$ abordam didaticamente as alternativas de ação ao alcance dos camponeses frente aos desmandos do proprietário: deixar a fazenda sem oferecer resistência, partir para o confronto violento contra os jagunços do coronel, optar por uma resistência organizada e, por fim a ação judicial $^{47}$. Diante da aliança do coronel com os representantes dos poderes públicos, os agricultores de Novo Sol chegam à conclusão de que a única opção que lhes resta é a oficialização de uma União de Lavradores e a divulgação de sua luta na imprensa. Para tanto, contam com o apoio de um jornalista especializado em movimentos sociais.

Julgamento em Novo Sol toca em temas sensíveis das décadas de 1950 e 1960 no Brasil: a posse da terra por latifundiários, suas alianças com os representantes dos poderes públicos e o nascimento dos sindicatos de trabalhadores rurais - em especial evidência devido à atuação das Ligas Camponesas. Tais temas são abordados a partir do uso de recursos do teatro épico brechtiano - como a representação em forma de julgamento, onde a preocupação central é instruir os espectadores, e a ausência de um desenlace conclusivo, uma vez que ao final da peça há a indicação de que a luta dos trabalhadores rurais continua ${ }^{48}$.

Em A Incelença, de autoria de Luís Marinho, peça seguinte encenada pelo TCP, mesmo com a mudança no estilo de encenação e situação retratada, o grupo ainda transita pelo universo dos trabalhadores rurais e suas relações com os latifundiários. Encenada pela primeira vez no Teatro de Santa Isabel, no dia 29 de dezembro de $1962^{49}$ a peça retrata um velório muito comum entre a população pobre de áreas rurais do Nordeste, no qual ao longo da noite são entoados cânticos (as incelenças), consideradas uma maneira de homenagear o morto ${ }^{50}$.

A Incelença é cantada no velório do agricultor Quirino, de forma que a narrativa se desenvolve em um único cenário: a sala da casa do falecido, onde há algumas cadeiras, bancos sem encosto, uma mesa - onde durante o velório são servidas comidas e bebidas - e uma imagem do Coração de Jesus pendurada na parede ${ }^{51}$. Em vez de um caixão, o corpo do morto é exibido num banco comprido e parcialmente coberto por uma mortalha.

Enquanto as incelenças são cantadas por um grupo de beatas, uma sequência de cenas exibe aspectos da vida da população rural. Apesar de não faltarem doses de humor aos diálogos e situações, é perceptível a crítica a valores e práticas da sociedade burguesa, como a propriedade privada e as formas de perpetuar a riqueza entre uma parcela da população. Para 
mostrar quão arraigados são esses valores e práticas na sociedade, a peça retratada uma pobre família de trabalhadores reproduzindo um dos dispositivos de perpetuação da riqueza: a disputa entre os filhos pela (pouca) herança do pai - um relógio de pulso e algumas cabeças de gado.

Em A Incelença os personagens estão conformados com a situação em que vivem. Nem mesmo a determinação do coronel em despejar a família do falecido do sítio arrendado onde moram é capaz de mudar a postura dos personagens: apesar de inicialmente se desesperar com o comunicado do coronel, a viúva acaba por acatar a ordem de despejo que só não é efetivada porque o coronel se interessa pela filha adolescente dos agricultores, que ao fim da narrativa é levada para morar na casa do coronel. Aqui, diferentemente de Julgamento em Novo Sol, não há trabalhadores rurais dispostos a enfrentar os desmandos e as vontades do coronel. No entanto, em ambas as peças são construídas imagens de uma realidade desigual do país com a intenção de sensibilizar a plateia e instigar a reflexão sobre a busca por mudanças.

\section{b) Os programas das peças}

Uma ida ao teatro no Recife da década de 1960 - principalmente se a casa de encenações em questão fosse o Teatro de Santa Isabel - era uma forma de entretenimento e fruição da arte revestida por uma série de aspectos formais. Um deles era a exigência do uso do paletó feita aos espectadores, que deixou de ser obrigatório apenas a partir da gestão de Miguel Arraes na Prefeitura do Recife - não sem causar protesto entre membros mais conservadores do campo teatral. Outra formalidade à qual os frequentadores do teatro estavam acostumados era a de receberem antes da encenação um programa da peça - espécie de livreto ou panfleto que continha informações técnicas sobre o grupo que estava prestes a se apresentar e, no mínimo, uma sinopse do espetáculo. Logo, os programas eram um espaço privilegiado de comunicação, onde o grupo teatral podia expor suas concepções sobre as artes cênicas, sua proposta enquanto grupo teatral e/ou justificar a escolha do texto encenado.

Ao lermos o programa de A Incelença vemos que o TCP percebe a sua encenação como uma oportunidade para denunciar o que chama estado de "alienação cultural" em que vivem os pequenos agricultores, do qual a passividade frente ao coronel e a persistência na prática das incelenças são entendidas como um sintoma de tal estado ${ }^{52}$. A leitura dos programas das peças figura como ferramenta fundamental para entender o papel desempenhado pelo TCP na política cultural do governo de Miguel Arraes, uma vez que revelam as intenções presentes na 
escolha dos textos a serem levados ao palco e as representações que produziram da realidade. Os programas eram um meio de explicitar e reforçar a visão do grupo sobre o espetáculo ao mesmo tempo em que disseminava a sua percepção da realidade brasileira de então.

O programa de Julgamento em Novo Sol, além das informações técnicas e das canções do espetáculo exibiu uma sinopse escrita por Nelson Xavier, onde expunha sua intenção ao escrever o espetáculo de criar um retrato verdadeiro da realidade vivida pelo lavrador brasileiro. Ao mesmo tempo, aproveita para denunciar de maneira direta as perseguições sofridas por lideranças desses trabalhadores ao se referir ao assassinato do líder das Ligas Camponesas de Sapé, na Paraíba, João Pedro Teixeira, ocorrido em abril de $1962^{53}$.

Antes de passarmos a terceira modalidade de ação de que trataremos - os autos de conscientização e os esquetes - um terceiro exemplo de programa de espetáculo nos permite expressar a postura estética e política do TCP e a representação da realidade construída pelo grupo. Trata-se do programa produzido para a peça A Derradeira Ceia, também de Luís Marinho. No programa distribuído durante uma temporada no Teatro de Santa Isabel, iniciada em 24 de julho de 1962, lemos o seguinte texto, assinado por Luiz Mendonça, diretor da montagem:

[...] Lampião com todo o cotejo de males que impôs a muitas inocentes famílias nordestinas, não foi responsável pelos crimes que praticou. Foi vítima do meio social em que viveu.

Lampião foi o símbolo da rebeldia contra as injustiças. Em sua rebeldia praticou o mal contra os inocentes que se tornaram assim vítimas não de Lampião e seus fiéis seguidores, mas das contradições existentes em nossa sociedade.

"A Derradeira Ceia" retrata em linhas simples e com diálogo vivo, quanto autêntico, aspectos da vida de Lampião e seu bando. Aborda fatos que se universalizam não somente no seu espírito de rebeldia, mas também nas particularidades dos implicados nesses fenômenos. Saturnino, Nazinha, Lampião, Maria Bonita e todo o seu bando formam o complexo fenômeno do cangaceirismo [sic], filho direto e inseparável de uma política agrária que não evoluiu de acordo com o desenvolvimento da sociedade [grifo nosso]. ${ }^{54}$

O argumento central da sinopse é a crítica social, desenvolvida ao longo de quatro parágrafos. Nela, há traços de uma leitura marxista da sociedade demonstrada pelo uso do termo "contradição". Utilizando-se da dialética marxista, o diretor inocenta Lampião e seu bando de suas ações, tornando-os vítimas de uma sociedade atrasada e excludente, sobre a qual recai a culpa pelos atos violentos dos cangaceiros. Em suma, nos programas entregues durante as encenações do TCP prevalece a representação de uma sociedade atrasada, resultado do latifúndio e do descaso do governo central e a necessidade urgente de mudar aquele estado de coisas. 


\section{c) Autos de conscientização e esquetes}

Além de peças cuja estrutura dramática é mais elaborada - como A Derradeira Ceia, Julgamento em Novo Sol e A Incelença - o TCP também explorou formas cênicas dotadas de uma estrutura mais simples, porém com grande potencial de comunicação com o público, seja por adotarem um discurso direto com a plateia, seja por demandar poucos recursos para encenação, o que permitia que o grupo se apresentasse em teatros de bairro, na carroceria de caminhões ou no meio da rua, descentralizando sua prática teatral. Essas peças curtas foram chamadas por Nelson Xavier de autos de conscientização ${ }^{55}$.

Nelson Xavier afirma que após dirigir Julgamento em Novo Sol seu trabalho junto ao TCP consistiu principalmente na criação e montagem desses autos que eram "pretextos ou estímulos para discussões sobre o poder do voto, sobre artigos da Constituição Federal, Declaração Universal dos Direitos do Homem, ou problemas do bairro, como o abastecimento de água [...]" $]^{, 56}$. Um desses autos, chamado Auto do indivíduo analfabeto de pai e mãe, de autoria de José Wilker, foi apresentado como número de abertura da peça A Incelença na temporada de 1962. No programa entregue aos espectadores, aparece a seguinte sinopse sobre o Auto:

Pretendemos mostrar através do teatro a alienação à que conduz o analfabetismo. Assim, é nossa pretensão abordar esse tipo de doença social em seus diversos lados: ridículo, grotesco, trágico e inumano. Com esse auto que apresentamos hoje, queremos destacar aquele primeiro aspecto, reprovando ainda a existência do analfabetismo na pátria brasileira. ${ }^{57}$

A sinopse transcrita acima reforça a definição dada por Nelson Xavier sobre os autos de conscientização: denúncias que visavam estimular discussões sobre problemas nacionais.

Além dos autos, o TCP também criou e encenou esquetes, que são cenas curtas, nas quais são discutidos determinados temas escolhidos previamente ${ }^{58}$. No caso do TCP, havia o interesse declarado em seu plano de ação para 1963 em montar esquetes que abordassem temas políticos, o que aproxima sua prática do agit-prop ${ }^{59}$. Devido à importância dada a esse trabalho com esquetes de agit-prop, foi criado no Teatro Cultura Popular um núcleo voltado para o estudo e a elaboração dessas cenas $\operatorname{curtas}^{60}$. Logo, nem todos os integrantes do Teatro de Cultura Popular participaram das atividades de agitação e propaganda ${ }^{61}$.

A ausência de material preservado relativo aos autos e aos esquetes produzidos pelo TCP - como os textos originais - dificulta a investigação de maiores detalhes sobre os mesmos. No entanto, Luiz Mendonça relata em um depoimento publicado no caderno especial n² - Teatro e Realidade Brasileira -, da Revista Civilização Brasileira, que o grupo 
apresentara esquetes em comícios, onde o que era dito pelos atores "era mais entendido do que os discursos dos oradores oficiais ${ }{ }^{62}$. Apesar de pouco precisa em detalhes, a fala de Luiz Mendonça é reveladora não apenas da participação dos integrantes do MCP/TCP nas campanhas eleitorais do período, como da relevância que a prática teatral do grupo adquiriu no que se refere à propaganda política dos candidatos apoiados pela Frente do Recife.

A ex-integrante do MCP, Liana Aureliano, em entrevista cedida na década de 1980, rememora a participação de membros do MCP/TCP na campanha eleitoral de Miguel Arraes para governador de Pernambuco, em 1962. Segundo relata, os comícios eram abertos por uma apresentação do coral falado do MCP seguida pelos esquetes encenados por uma parte dos integrantes do Teatro de Cultura Popular ${ }^{63}$. Embora não se lembre de todos os nomes, afirma que Luiz Mendonça, Ilva Niño, Tereza Calazans, Moema Cavalcanti, José Wilker e Delmiro Lira compunham o núcleo do TCP que participava dos comícios ${ }^{64}$.

Liana indica ainda que, embora fossem membros do TCP/MCP, a participação na campanha de Arraes não era anunciada como uma atividade oficial do Movimento de Cultura Popular $^{65}$. Essa observação pode ser entendida como uma tentativa de reforçar o discurso que sustentava o MCP como um órgão de caráter exclusivamente técnico e "apolítico"66. A participação de membros do MCP na campanha política de Miguel Arraes para governador do estado de 1962 também é mencionada na autobiografia do advogado e líder comunista Paulo Cavalcanti, que afirma que, apesar de não se pronunciar oficialmente por nenhum dos candidatos, "o grosso do pessoal do Movimento de Cultura Popular engajou-se na campanha, organizando shows, pequenas encenações de peças teatrais e outras manifestações do gênero $[\ldots]^{, 67}$.

Além dos esquetes utilizados em comícios, outros foram escritos a pedido de Paulo Freire para ilustrar palestras, aulas e reuniões dos círculos de cultura e das campanhas de alfabetização - o que sinaliza a cooperação entre os diferentes departamentos do $\mathrm{MCP}^{68}$. Por exemplo, em ofício de 27 de fevereiro de 1964, Luiz Mendonça comunica que o TCP preparou duas peças curtas para colaborar com a Campanha de Alfabetização a ser iniciada por cidades do interior de Pernambuco a partir de março daquele ano. As peças eram: Estória do Formiguinho e sua porta, de Arnaldo Jabor, adaptada pelo próprio Luiz Mendonça e Paixão e morte do vaqueiro Manoel Onofre, escrito por José Wilker ${ }^{69}$. Sobre a participação do TCP nessa campanha assevera: 
tradições populares desse mesmo povo, para que ele possa melhor identificar-se com suas formas populares de arte e com a realidade brasileira atual. ${ }^{70}$

Antes, ainda em 1962, na III Semana Estudantil de Cultura Popular, após encenarem Julgamento em Novo Sol, parte do elenco do TCP também apresentou duas dramatizações: Auto dos $99 \%$ e A balada do subdesenvolvimento. A primeira ilustrou a palestra Educação não é um privilégio, ministrada no dia 10 de maio de 1962, por Anita Paes Barreto, Paulo Freire, Germano Coelho, Pe. Almeri Bezerra, Tanceta Figueiredo, Fernando Teixeira, Antônio Maciel e André Altino ${ }^{71}$. Já A balada do subdesenvolvimento integrou o painel da sexta feira, dia 11 de maio de 1962, chamado Cultura para a emancipação do povo, apresentado por Germano Coelho, Celia Freire, Manuel Correia, Gerson Maciel e o Pe. Aluísio Guerra ${ }^{72}$.

\section{Considerações finais}

O sociólogo Pierre Bourdieu define o poder simbólico como o "poder de fazer coisas com as palavras" $"$. Destaca ainda que o espaço simbólico de uma sociedade é organizado segundo a lógica das diferenças existentes entre os diversos grupos que o compõe, originando-se aí as lutas simbólicas que visam moldar as formas de percepção da realidade a partir do poder simbólico de cada um desses grupos. Embora afirme ser impossível para qualquer das partes envolvidas nessas lutas estabelecerem um monopólio sobre o campo simbólico, Bourdieu admite que a parte que detém o controle de estruturas como o Estado pode obter uma vantagem na disputa que lhe permita transformar o poder simbólico que detém em poder de constituição, "um poder de conservar ou transformar as classificações atuais em matérias de sexo, nação, região, idade e estatuto social, e isso através das palavras que são utilizadas para designar ou descrever os indivíduos, os grupos ou instituições"74.

É possível perceber que a criação do Teatro de Cultura Popular (TCP), bem como numa escala mais ampla do Movimento de Cultura Popular (MCP), dotou os grupos políticos reunidos em torno do governo de Miguel Arraes de estruturas capazes de intervir nas relações de poder simbólico e, consequentemente, alterar a percepção da realidade dos indivíduos. Em contraposição à imagem de conspiradores do comunismo internacional surge outra: a de pessoas dos mais variados lugares sociais unidas para mudar a realidade desigual em que viviam. Realidade que buscavam retratar, ou antes, denunciar em sua prática teatral fosse por meio do que era levado à cena ou pelo material que produziram para os espetáculos - como os 
programas das peças. Indivíduos dispostos a cooperar não apenas pelo desenvolvimento econômico, mas pelo humano.

Constatamos que para os membros do TCP a arte teatral possuía um papel social e político a desempenhar. Não podia adotar posturas que se revestem de uma neutralidade artística fictícia para obter vantagens ou chancela, uma vez que entendiam o teatro como um veículo de educação e informação para o povo, capaz de operar mudanças políticas e sociais portanto, uma arte com potencial revolucionário. E é por perceberem que as forças políticas representadas nas gestões de Miguel Arraes estavam, mais ou menos, afinadas com os mesmos ideais de mudança social que aqueles jovens artistas se reuniram no Teatro de Cultura Popular. Como anunciava o programa de Julgamento em Novo Sol, a causa do grupo podia ser resumida da seguinte maneira: "teatro e cultura para a emancipação do povo"75.

Olhando retrospectivamente para o papel de instância legitimadora das gestões de Miguel Arraes desempenhado pelo TCP é difícil não questionar quais os limites na concepção revolucionária da prática teatral do grupo que podem ter surgido devido ao lugar que ocupava na estrutura administrativa. Esse questionamento nos remete a uma análise genealógica das iniciativas de teatro popular na França realizada pelo teatrólogo Bernard Dort e publicada em 1969 na revista Cahiers Théâtre Louvain. Dort discorda dos teóricos que enxergam o teatro, ainda que se refiram ao "teatro popular", como algo essencialmente revolucionário. Nesse sentido, o autor afirma que o teatro deve ser visto como "um instrumento político muito perigoso", uma vez que "ele não é em conjunto contestatório; não o foi durante séculos. Em todos os regimes monárquicos o teatro foi um instrumento de consagração social, seu modo de participação era a consagração do poder"76. Era exatamente de um "instrumento de consagração social" que as forças políticas reunidas na gestão de Miguel Arraes precisavam para se contrapor às representações depreciativas - comunistas, subversivos - disseminadas a seu respeito, modificando assim as disposições dos agentes sociais, seu habitus, aquelas "estruturas mentais através das quais eles apreendem o mundo social" 77 , uma vez que tais estruturas, afirma Bourdieu, possuem uma gênese social ${ }^{78}$.

Considerando o que foi exposto até aqui, entendemos que ao desenvolver uma prática teatral contestatória, definida como revolucionária e interessada na problematização de temáticas sociais, o Teatro de Cultura Popular atuava, sobretudo, como elemento de consagração de um novo grupo no poder. 


\section{Notas}

1 Arquivo BNM-DIGITAL. Termo de perguntas ao indiciado. 02/09/1964. Disponível em http://bnmdigital.mpf.mp.br/pt-br/. Acessado em 25/02/2015.

${ }^{2}$ Idem, ibidem.

${ }^{3}$ Entrevista cedida por Carlos Reis em 11/04/2015.

${ }^{4}$ Sobre a atuação dos órgãos de vigilância ver: SILVA, Marcília Gama da. Informação, repressão e memória: a construção do estado de exceção no Brasil da perspectiva do DOPS-PE (1964-1985). Recife: Editora UFPE, 2014.

${ }^{5}$ Para maiores esclarecimentos sobre os conceitos de estratégia e tática ver: CERTEAU, Michel de. A Invenção do cotidiano: 1 - Artes de fazer. 19a ed. Tradução de Ephraim Ferreira Alves. Petrópolis: Vozes, 2012.

${ }^{6}$ GUÉNOUN, Denis. A exibição das palavras: uma ideia (política) do teatro. Tradução: Fátima Saad. Rio de Janeiro: Teatro do Pequeno Gesto, 2003. p. 14.

${ }^{7}$ WILlIAMS, Raymond. Cultura e Materialismo. Tradução de André Glaser. São Paulo: Editora Unesp, 2011, p. 65.

${ }^{8}$ Programa da peça A Bomba da Paz. Acervo pessoal de Luís Reis.

${ }^{9}$ APEJE. Hemeroteca. Jornal Diario de Pernambuco. 16/12/1959.

${ }^{10}$ Idem, ibidem.

11 SANTOS, Taciana Mendonça. Alianças Políticas em Pernambuco: a(s) frente(s) do Recife (1955-1964). Recife, 2008. Dissertação (Mestrado em História). Universidade Federal de Pernambuco.

${ }^{12}$ Idem, ibidem.

${ }^{13}$ ROZOWIKWIAT, Maria Tereza Gondim. Arraes: duas mãos e o sentimento do mundo. In Clio - Revista de Pesquisa Histórica. N. 22, 2004, p. 63-84. Recife: Editora Universitária da UFPE.

${ }^{14}$ CAVALCANTI, Paulo. O caso eu conto como o caso foi: da coluna Prestes à queda de Arraes: Memórias políticas. 4 ed. Revista e ampliada. Recife: CEPE, 2008, p. 295.

${ }^{15}$ DABAT, Christine Rufino. Ligas Camponesas e sindicatos de trabalhadores rurais: a luta de classes na zona canavieira de Pernambuco segundo os cortadores de cana. In Clio - Revista de Pesquisa Histórica. N. 22, 2004, p. 149 - 188. Recife: Editora Universitária da UFPE.

${ }^{6}$ MOTTA, Rodrigo Patto Sá. Em guarda contra o perigo vermelho: o anticomunismo no Brasil (1917-1964). São Paulo: Perspectiva, 2002.

${ }^{17}$ WILLIAMS, Raymond. Cultura e Materialismo. Tradução de André Glaser. São Paulo: Editora Unesp, 2011, p. 53.

${ }_{18}$ Idem, ibidem.

${ }^{19}$ PORFÍRIO, Pablo. Medo, Comunismo e Revolução: Pernambuco (1959 - 1964). Recife: Editora Universitária da UFPE, 2009.

${ }^{20}$ Idem, ibidem.

21 FUNDAÇÃO BIBLIOTECA NACIONAL. Hemeroteca digital. O Cruzeiro. 07/07/1962. Acesso em 09/04/2014

${ }^{22}$ Idem, p 35 .

${ }^{23}$ Lançada em 10 de dezembro de 1928 pela rede de Diários Associados de Assis Chateaubriand - a qual também pertencia o Diario de Pernambuco -, a revista ilustrada $O$ Cruzeiro circulou até meados da década de 1970. Durante muitos anos foi a principal revista ilustrada publicada no Brasil, chegando a uma tiragem semanal que variava de 50 a 80 mil exemplares. Ver: Secretaria Especial de Comunicação Social. Cadernos da comunicação: série memória. Rio de Janeiro - O Cruzeiro - A maior e melhor revista da América Latina. Junho de 2002. Disponível em <http://www.rio.rj.gov.br/dlstatic/10112/4204434/4101414/memoria3.pdf〉. Acesso em $15 / 03 / 2016$

${ }^{24}$ PORFÍRIO, Pablo. Op. cit., p. 89.

${ }^{25}$ BOURDIEU. Pierre. Espaço social e poder simbólico. In BOURDIEU, Pierre. Coisas ditas. Tradução: Cássia R. da Silveira e Denise Moreno Pegorim; revisão técnica Paula Monteiro. São Paulo: Brasiliense, 2004. p. 158

${ }^{26}$ BOURDIEU. Pierre. Op cit., p. 163.

${ }^{27}$ BOBBIO, Norberto. Política e Cultura. Organização: Franco Sbarberi; tradução Jaime A. Clasen. $1^{\text {a }}$ Ed. São Paulo: Editora Unesp, 2015, p. 91.

${ }^{28}$ URFALINO, Philippe. A história da política cultural. In RIOUX, Jean-Pierre; SIRINELLI, Jean-François. Para uma história cultural. Lisboa: Estampa, 1998, p.: 293-306.

${ }^{29}$ Idem, p. 296.

${ }^{30}$ Estatuto do MCP. In COELHO, Germano. MCP: história do Movimento de Cultura Popular. Recife: Ed. do autor, 2012, p. 214.

${ }^{31}$ Estatuto do MCP. APEJE. Acervo DOPS-PE, prontuário funcional no 1501-D, fundo: 29.841. 
${ }^{32}$ Idem, ibidem.

${ }^{33}$ NIÑO, Ilva. Entrevista concedida à Paula Autran e Sara Melo Neiva em julho de 2015. In: XAVIER, Nelson. Mutirão em Novo Sol. $1^{\mathrm{a} e d}$. São Paulo: Expressão Popular, 2015. p. 158.

${ }^{34}$ CAVALCANTI, Moema. Depoimento concedido à Paula Autran, Paulo Fávari e Sérgio de Carvalho em Julho de 2015. In XAVIER, Nelson. Op. cit., p.149.

${ }^{35}$ Idem, p. 150.

36 TELLES, Narciso. Um teatro para o povo: a trajetória do Teatro de Cultura Popular de Pernambuco. In Artcultura. Uberlândia, v. 1, n. 1, p. 33, julho 1999.

${ }^{37}$ APEJE. Hemeroteca. Jornal Diario de Pernambuco. 13/02/1962.

${ }^{38}$ RIDENTI, Marcelo. Brasilidade Revolucionária: um século de cultura e política. São Paulo: Editora UNESP, 2010 , p. 87.

${ }^{39}$ Idem, p. 88.

${ }^{40}$ Idem, p. 91.

${ }^{41}$ LEITE, Sebastião Uchoa. Cultura Popular: esboço de uma resenha crítica. Revista Civilização Brasileira. Rio de Janeiro, ano I, n. 4, p. 269-289. Setembro, 1965.

42 Idem, ibidem.

${ }^{43}$ Além de Nelson Xavier, também participaram da escrita da peça: Augusto Boal, Benedito Araújo, Hamilton Trevisan e Modesto Carone.

${ }^{44}$ XAVIER, Nelson. Meus anos dourados foram no MCP. In COELHO, Germano. Op. cit., p.XXXIII.

45 BOAS, Rafael Litvin Villas. Teatro Político e questão agrária: contradições, avanços e impasses de um momento decisivo. Programa de Pós-Graduação em Teoria Literária e Literaturas - UNB. 2009. Tese (Doutorado). 233 págs.

${ }^{46}$ Idem, p. 71.

${ }^{47}$ Idem, p. 76.

${ }^{48}$ Idem, p. 72.

49 APEJE. Hemeroteca. Jornal Última Hora - Nordeste. 30/12/1962.

50 FALCÃO, Luiz Marinho. Entrevista concedida à Cristina Inojosa. In Pernambuco 50 anos de teatro. Fundação Joaquim Nabuco, p. 14.

${ }^{51}$ MARINHO. Luiz. A Incelença. Edição Nordeste: Recife, 1968, p. 04.

52 Arquivo pessoal de Leidson Ferraz. Acervo Projeto Teatro Tem Programa!. Programa da peça A Incelença.

53 APEJE. Hemeroteca. Diario de Pernambuco. 05/04/1962.

${ }^{54}$ Arquivo pessoal de Leidson Ferraz. Acervo Projeto Teatro Tem Programa!. Programa da peça A Derradeira Ceia.

${ }^{55}$ XAVIER, Nelson. Op. cit.. In COELHO, Germano. Op. Cit., p. XXXV.

${ }^{56}$ Idem, ibidem.

${ }^{57}$ Arquivo pessoal de Leidson Ferraz. Acervo Projeto Teatro Tem Programa!. Programa da peça A Incelença.

${ }^{58}$ PAVIS, Patrice. Dicionário de teatro. Trad. J Guinsburg e Maria Lúcia Pereira. São Paulo: Perspectiva, 2015. p. 143.

59 Termo derivado das palavras agitação e propaganda. Designa formas de agitação teatral surgidas durante a revolução russa de 1917 e que foram bastante exploradas nos primeiros anos da União Soviética, bem como na Alemanha, entre 1919 e 1933. O objetivo dos agit-props era sensibilizar o público em relação a uma determinada situação social ou política. Ver: PAVIS, Patrice. Op. cit., p. 379.

${ }^{60}$ TELLES, Narciso. Op. cit., p. 30.

${ }^{61}$ Idem, ibidem.

62 MENDONÇA, Luiz. Op. cit., p. 149-159. Disponível em: <http://forumeja.org.br/df/sites/forumeja.org.br.df/files/depluiz.pdf >. Acesso em 04/04/2013, p. 156.

63 AURELIANO, Liana. Depoimento concedido ao projeto "História Oral do Movimento Politico Militar de 1964 no Nordeste”, em 17/10/1986. CEHIBRA, Fundação Joaquim Nabuco, p. 11.

${ }^{64}$ Idem, ibidem.

${ }^{65}$ É preciso ressaltar que, embora o MCP contasse com grande contingente de voluntários, principalmente no que se referia às campanhas de alfabetização, alguns de seus membros eram funcionários assalariados pelo Movimento. Por exemplo, o ator José Wilker, segundo aponta Liana Aureliano, recebia um pequeno salário do MCP por sua participação no Teatro de Cultura Popular. Ver: Idem, Ibidem.

${ }^{66}$ APEJE. Hemeroteca. Jornal do Commercio. 09/09/1962.

${ }^{67}$ CAVALCANTI, Paulo. O caso eu conto como o caso foi: da coluna Prestes à queda de Arraes: Memórias políticas. $4^{\mathrm{a}}$ ed. Revista e ampliada. Recife: CEPE, 2008, p. 339.

68 MENDONÇA, Luiz. Op. $\quad$ cit., $\quad$ p. $156 . \quad$ Disponível em: <http://forumeja.org.br/df/sites/forumeja.org.br.df/files/depluiz.pdf>. Acesso em 04/04/2013. 


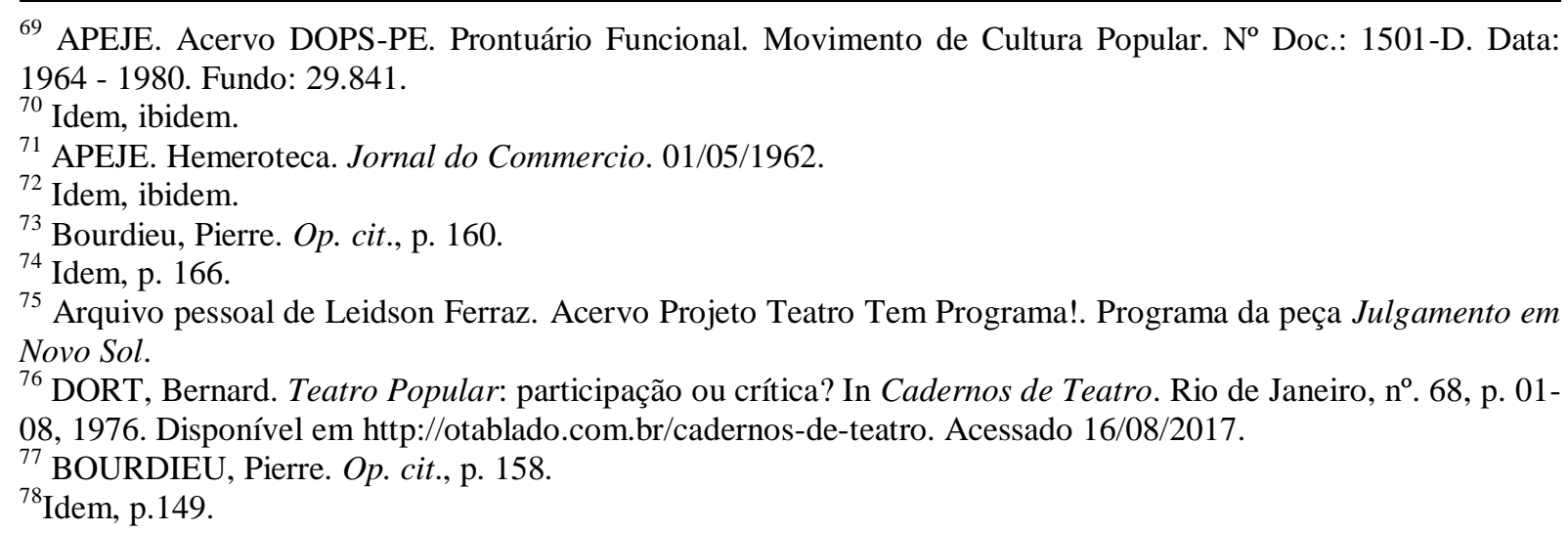

\section{Referências Bibliográficas}

BARBOSA, Letícia Rameh. Movimento de Cultura Popular: impactos na sociedade pernambucana. Recife. Editora do autor, 2009.

BOAS, Rafael Litvin Villas. Teatro Político e questão agrária: contradições, avanços e impasses de um momento decisivo. Programa de Pós-Graduação em Teoria Literária e Literaturas - UNB. 2009. Tese (Doutorado). 233 págs.

BOBBIO, Norberto. Política e Cultura. Organização: Franco Sbarberi; tradução Jaime A. Clasen. $1^{\text {a }}$ Ed. São Paulo: Editora Unesp, 2015.

BOURDIEU. Pierre. Espaço social e poder simbólico. In BOURDIEU, Pierre. Coisas ditas. Tradução: Cássia R. da Silveira e Denise Moreno Pegorim; revisão técnica Paula Monteiro. São Paulo: Brasiliense, 2004. p. 149-168.

CAVALCANTI, Paulo. O caso eu conto como o caso foi: da coluna Prestes à queda de Arraes: Memórias políticas. $4^{\mathrm{a}}$ ed. Revista e ampliada. Recife: CEPE, 2008.

CERTEAU, Michel de. A Invenção do cotidiano: 1 - Artes de fazer. $19^{a}$ ed. Tradução de Ephraim Ferreira Alves. Petrópolis: Vozes, 2012.

COELHO, Germano. MCP: História do Movimento de Cultura Popular. Recife: Ed. Do Autor, 2012.

DABAT, Christine Rufino. Ligas Camponesas e sindicatos de trabalhadores rurais: a luta de classes na zona canavieira de Pernambuco segundo os cortadores de cana. In Clio - Revista de Pesquisa Histórica. N. 22, 2004, p. 149 - 188. Recife: Editora Universitária da UFPE.

DORT, Bernard. Teatro Popular: participação ou crítica? In Cadernos de Teatro. Rio de Janeiro, $\mathrm{n}^{\circ}$. 68, p. 01-08, 1976. Disponível em http://otablado.com.br/cadernos-de-teatro. Acessado 16/08/2017. 
FUNDAÇÃO JAQUIM NABUCO (FUNDAJ). Catálogo dos depoimentos do programa de história oral da Coordenação-geral de Estudos da História Brasileira Rodrigo Melo Franco de Andrade (CEHIBRA). Recife, 2012.

GUÉNOUN, Denis. A exibição das palavras: uma ideia (política) do teatro. Tradução: Fátima Saad. Rio de Janeiro: Teatro do Pequeno Gesto, 2003

LEITE, Sebastião Uchoa. Cultura Popular: esboço de uma resenha crítica. Revista Civilização Brasileira. Rio de Janeiro, ano I, n. 4, p. 269-289. Setembro, 1965.

MARINHO. Luiz. A Incelença. Edição Nordeste: Recife, 1968.

MENDONÇA, Luiz. Teatro é Festa para o Povo. Revista Civilização Brasileira - Caderno Especial $n^{\circ}$. 2. Rio de Janeiro: Civilização Brasileira, ano IV, p. 149-159, jul. 1968. Disponível em: <http://forumeja.org.br/df/sites/forumeja.org.br.df/files/depluiz.pdf>. Acesso em 04/04/2013.

MOTTA, Rodrigo Patto Sá. Em guarda contra o perigo vermelho: o anticomunismo no Brasil (1917-1964). São Paulo: Perspectiva, 2002.

PAVIS, Patrice. Dicionário de teatro. Trad. J Guinsburg e Maria Lúcia Pereira. São Paulo: Perspectiva, 2015.

PORFÍRIO, Pablo. Medo, Comunismo e Revolução: Pernambuco (1959 - 1964). Recife: Editora Universitária da UFPE, 2009.

RIDENTI, Marcelo. Brasilidade Revolucionária: um século de cultura e política. São Paulo: Editora UNESP, 2010.

ROZOWIKWIAT, Maria Tereza Gondim. Arraes: duas mãos e o sentimento do mundo. In Clio - Revista de Pesquisa Histórica. N. 22, 2004, p. 63-84. Recife: Editora Universitária da UFPE.

SANTOS, Taciana Mendonça. Alianças Políticas em Pernambuco: a(s) frente(s) do Recife (1955-1964). Recife, 2008. Dissertação (Mestrado em História). Universidade Federal de Pernambuco.

SILVA, Marcília Gama da. Informação, repressão e memória: a construção do estado de exceção no Brasil da perspectiva do DOPS-PE (1964-1985). Recife: Editora UFPE, 2014.

TELLES, Narciso. Um teatro para o povo: a trajetória do Teatro de Cultura Popular de Pernambuco. In Artcultura. Uberlândia, v. 1, n. 1, p. 33, julho 1999.

URFALINO, Philippe. A história da política cultural. In RIOUX, Jean-Pierre; SIRINELLI, Jean-François. Para uma história cultural. Lisboa: Estampa, 1998, p.: 293-306.

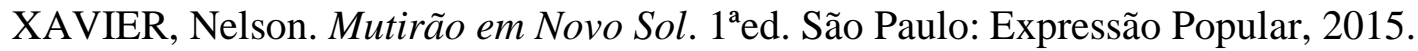


WILLIAMS, Raymond. Cultura e Materialismo. Tradução de André Glaser. São Paulo: Editora Unesp, 2011. 